\title{
Anomalies in VLF radio signals prior the Abruzzo earthquake ( $M=6.3$ ) on 6 April 2009
}

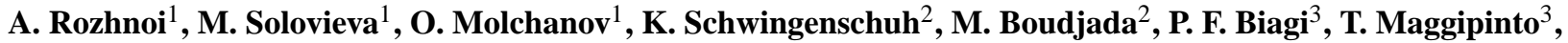 \\ L. Castellana ${ }^{3}$, A. Ermini ${ }^{4}$, and M. Hayakawa ${ }^{5}$ \\ ${ }^{1}$ Institute of the Physics of the Earth, Russian Academy of Sciences, Moscow, Russia \\ ${ }^{2}$ Space Research Institute Austrian Academy of Sciences, Graz, Austria \\ ${ }^{3}$ Department of Physics, University of Bari, Bari, Italy \\ ${ }^{4}$ Department of Mechanical Engineering, University of Roma Tor Vergata, Rome, Italy \\ ${ }^{5}$ Research Station on Seismo Electromagnetics, University of Electro-Communications, Chofu, Tokyo, Japan
}

Received: 16 July 2009 - Accepted: 30 September 2009 - Published: 21 October 2009

\begin{abstract}
The VLF/LF radio signals method for studying preseimic activity is applied to the Abruzzo earthquake ( $M=6.3$, 6 April 2009). The data collected by three receivers located in Moscow (Russia), Graz (Austria) and Bari (Italy) at about $3000 \mathrm{~km}, 1000 \mathrm{~km}$ and $500 \mathrm{~km}$ from the epicenter were used. The signals received from the Sardinia $(20.27 \mathrm{kHz})$ and the Sicily $(45.9 \mathrm{kHz})$ transmitters, both located in Italy, were compared with those received from the Iceland $(37.5 \mathrm{kHz})$, the Great Britain $(19.58 \mathrm{kHz})$ and the Germany $(23.4 \mathrm{kHz})$ transmitters. The propagation paths of the two Italian transmitters cross the epicentral area (seismic paths) unlike the paths of the other three signals (control paths). Using two different analyses, that are the study of the night-time signal and the research of shifts in the evening terminator times, clear anomalies were revealed $2-8$ days before the occurrence of the Abruzzo earthquake in the seismic paths, while no anomalies have been found in the control paths.
\end{abstract}

\section{Introduction}

The method of monitoring the phase and the amplitude of the radio signals radiated from VLF/LF $(15-60 \mathrm{kHz})$ transmitters and propagating inside the earth-ionosphere waveguide, is well known in radio physics. If the transmitter frequency and the transmitter-receiver distance is fixed, then the parameters of the observed signal are mainly dependent on the value and gradients of the electron density near the atmosphere-ionosphere boundary (typically $80-85 \mathrm{~km}$ ), that is the reflection zone of the signal. In case of some local per-

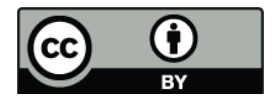

Correspondence to: A. Rozhnoi (rozhnoi@ifz.ru) turbation in this zone, anomalies can appear in the radio signals when the projection of the perturbed area on the ground surface is inside the elliptical signal sensitivity zone (Fresnel zone) elongated from the transmitter to the receiver. Therefore, the VLF/LF radio signal method has become the standard method for monitoring the short-time variations of the electron density in the lower ionosphere/upper atmosphere connected with the solar radiation, the cosmic rays, the precipitation of energetic particles, the lightning-induced ionization and the nuclear tests.

The first suggestion to use this method for studying possible effects related with the earthquakes was proposed by Russian researchers about 20 years ago (Gokhberg et al., 1989; Gufeld et al., 1992). The nighttime bay-like phase anomalies for long paths (receiver-transmitter distances greater than $3000 \mathrm{~km}$ ) were analyzed. Then, Japanese and Russian researchers have presented several results on anomalies in the VLF/LF radio propagation probably associated with the occurrence of earthquakes (see e.g. overview in the recent book by Molchanov and Hayakawa, 2008). At present, two different procedures exist for finding the radio signal anomalies related to the seismic activity. The first is a modification of the old Russian method and it relies on the analysis of the difference between the regular and the real nighttime values of the radio signal intensity. The difference is claimed as an anomaly if it exceeds some level (usually $2 \sigma$ level, where $\sigma$ is the standard deviation). A detailed description of this method is reported in Rozhnoi et al. (2004). The other method is the analysis of the terminator time (TT) in the daily variations (sunrise and sunset) of the radio signal intensity, that is described in Hayakawa et al. (1996). Such a procedure has proved itself as an efficient tool for finding precursors in connection with several large earthquakes in Japan (Hayakawa et al., 1996, 2005; Maekawa et al., 2006; Molchanov and Hayakawa, 1998; Rozhnoi et al., 2005). This

Published by Copernicus Publications on behalf of the European Geosciences Union. 
Table 1. Foreshocks and aftershocks $(M \geq 4.0)$ of the Abruzzo earthquake, from 26 March to 17 April 2009. The main earthquake is also indicated (bold).

\begin{tabular}{clllrl}
\hline Date & $\begin{array}{l}\text { Time } \\
(\mathrm{UT})\end{array}$ & Lat & Long & $\begin{array}{r}\text { Depth } \\
(\mathrm{km})\end{array}$ & $M$ \\
\hline 30 Mar 2009 & $13: 38: 38$ & 42.50 & 13.50 & 2 & 4.4 \\
5 Apr 2009 & $20: 20: 52$ & 44.35 & 11.98 & 6 & 4.6 \\
5 Apr 2009 & $20: 48: 57$ & 42.40 & 13.41 & 10 & 4.0 \\
6 Apr 2009 & $\mathbf{0 1 : 3 2 : 3 9}$ & $\mathbf{4 2 . 3 3}$ & $\mathbf{1 3 . 3 3}$ & $\mathbf{8}$ & $\mathbf{6 . 3}$ \\
6 Apr 2009 & $02: 27: 46$ & 42.37 & 13.34 & 10 & 4.2 \\
6 Apr 2009 & $02: 37: 04$ & 42.37 & 13.34 & 10 & 4.9 \\
6 Apr 2009 & $03: 56: 45$ & 42.34 & 13.39 & 10 & 4.4 \\
6 Apr 2009 & $07: 17: 10$ & 42.35 & 13.37 & 9 & 4.3 \\
6 Apr 2009 & $21: 56: 53$ & 42.40 & 13.32 & 9 & 4.1 \\
6 Apr 2009 & $22: 47: 13$ & 42.35 & 13.29 & 11 & 4.1 \\
6 Apr 2009 & $23: 15: 37$ & 42.45 & 13.36 & 8 & 4.9 \\
7 Apr 2009 & $09: 26: 30$ & 42.34 & 13.36 & 10 & 4.9 \\
7 Apr 2009 & $17: 47: 38$ & 42.35 & 13.45 & 17 & 5.5 \\
7 Apr 2009 & $21: 34: 29$ & 42.38 & 13.38 & 7 & 4.6 \\
8 Apr 2009 & $04: 27: 41$ & 42.31 & 13.47 & 10 & 4.1 \\
8 Apr 2009 & $22: 56: 50$ & 42.51 & 13.36 & 10 & 4.1 \\
9 Apr 2009 & $00: 52: 59$ & 42.48 & 13.34 & 15 & 5.3 \\
9 Apr 2009 & $03: 14: 52$ & 42.34 & 13.44 & 18 & 4.3 \\
9 Apr 2009 & $04: 32: 44$ & 42.44 & 13.42 & 8 & 4.2 \\
9 Apr 2009 & $19: 38: 18$ & 42.54 & 13.30 & 10 & 5.2 \\
10 Apr 2009 & $03: 22: 22$ & 42.47 & 13.42 & 9 & 4.0 \\
13 Apr 2009 & $21: 14: 24$ & 42.50 & 13.36 & 7 & 4.9 \\
\hline
\end{tabular}

method seems more efficient than the first one for rather short distances, i.e. less than $1000 \mathrm{~km}$, and the results depend on the frequency selection. In this paper we have applied both the previous procedures for revealing possible precursors of the Abruzzo earthquake.

\section{Data}

On 6 April 2009 the Abruzzo earthquake took place with magnitude $M=6.3$ near L'Aquila city (Central Italy). Several shocks occurred before and after the occurrence of the earthquake. The pre-seismic activity appeared since the beginning of January 2009 and it intensified approaching to the date of the main shock; the aftershocks activity is still active. The list of foreshocks and aftershocks with $M \geq 4.0$ (http://earthquake.usgs.gov/eqcenter/) in the period 26 March-17 April is reported in Table 1.

The radio signals data collected in the framework of a cooperation among Austria, Italy and Russia were analyzed. Japanese OMNIPAL receivers are located in: Bari (Italy), operating since 2002, and in Graz (Austria), operating since October 2008. An UMSK receiver is located in Moscow (Russia) and it began a regular running on 26 March 2009. The equipments are similar among them and the main operation

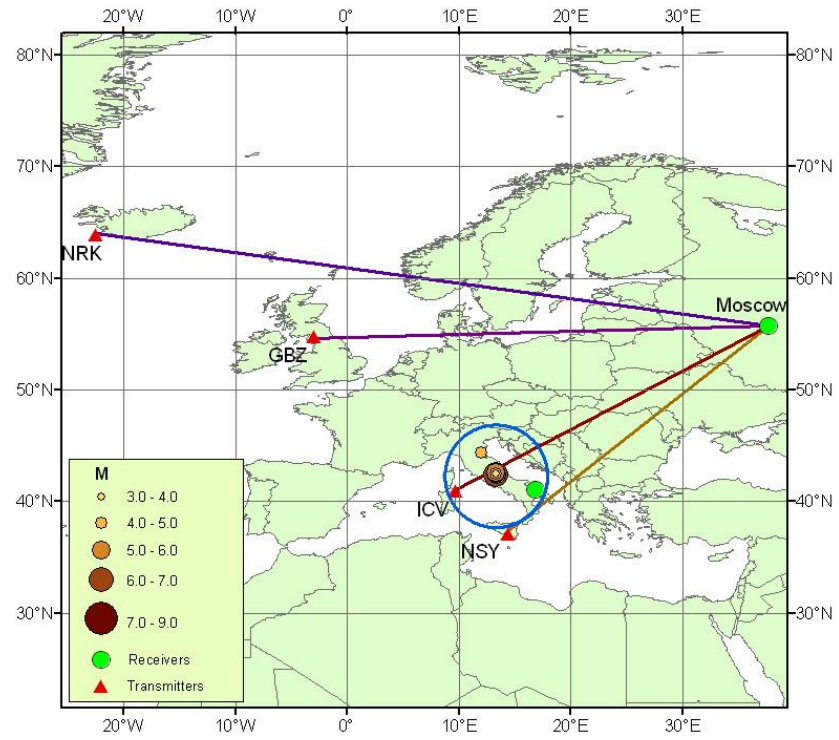

Fig. 1. Map showing the epicenters of the earthquakes occurred in the Abruzzo area in the period 1-9 April 2009. The blue circle represents the projection on the ground surface of the perturbed zone in the atmosphere-ionosphere boundary that approximately coincides with a zone of precursory activity. The seismic paths are related to the ICV (Sardinia, Italy) and NSY (Sicily, Italy) transmitters; the control paths are related to the GBZ (Great Britain) and NRK (Iceland) transmitters. The receiver in Moscow is indicated, too.

is detailed in Dowden and Adams (1989). In each station it is possible to collect the signals from several VLF/LF transmitters. Comparing the signals behavior along the so-called seismic paths, which cross the earthquake zone, and the control paths, aside of the previous zone, it is possible to produce the separation of the local anomalies from the large-scale ones, related with magnetic storms, meteorological events, and so on.

\section{Results and discussion}

Many empirical and theoretical estimations of the size of the zone on the ground, interested by a precursory activity were proposed in the past. In this framework, for a large earthquake as the Abruzzo one $(M=6.3)$, a circle of radius $R=500 \mathrm{~km}$ could be assumed (Molchanov and Hayakawa, 2008). In this study it was supposed that the size of the perturbed zone at the altitude $h=70-90 \mathrm{~km}$ of the VLF/LF radio signals reflection is about the same of the precursory activity ground zone. This hypothesis is reasonable if $R \gg h$.

At first the data collected by the Moscow receiver (MOS) were examined. Two transmitters located in Italy were selected for studying seismic paths: NSY $(f=45.9 \mathrm{kHz})$ in Sicily at a distance $D \sim 3000 \mathrm{~km}$ from the receiver and ICV $(f=20.27 \mathrm{kHz})$ in Sardinia at $D \sim 3500 \mathrm{~km}$. The control paths were related to the GBZ $(f=19.56 \mathrm{kHz}$, Great 


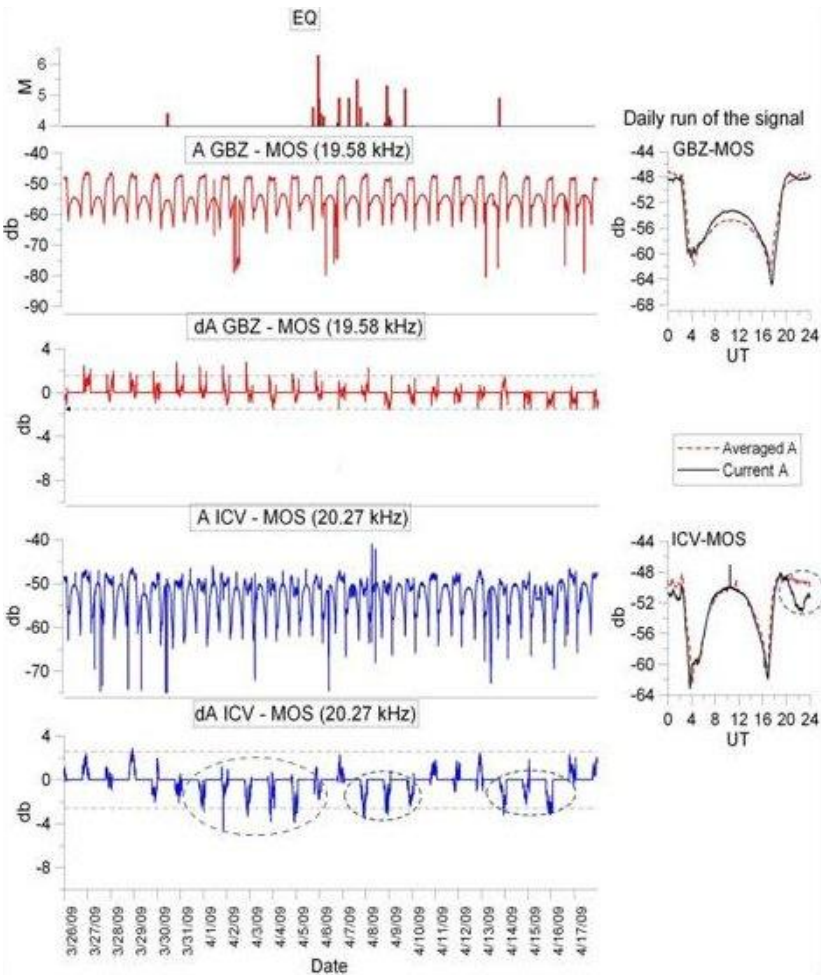

Fig. 2. In the upper panel the magnitude of the main Abruzzo earthquakes (Table 1) from 26 March to 17 April 2009 is indicated. In the next panels, the signal amplitude (A) and the nighttime residual amplitude (dA) for the path GBZ-MOS and ICV-MOS is reported. In the bottom panel the dashed ellipses indicate deviations of the real data from the averaged ones exceeding the $2 \sigma$ ( $\sigma$ is the standard deviation) level, that is depicted by horizontal dotted line. On the right, at the top an example of an averaged signal (for 5 undisturbed days) and of a real signal during a normal day is reported while at the bottom an example of anomaly is shown.

Britain, $D \sim 4000 \mathrm{~km})$ and the NRK $(f=37.5 \mathrm{kHz}$, Iceland, $D \sim 6000 \mathrm{~km})$ transmitters. The situation is shown in the Fig. 1, where the circle ( $\mathrm{R}$ radius) indicates the zone interested by the precursory activity. The widths of the VLF signal sensitivity zones (Fresnel zones) are much smaller (less $100 \mathrm{~km}$ ) than $R$ and they are not shown in the Fig. 1 .

For the Moscow data, only the first procedure of analysis mentioned in the Sect. 1 was applied. The results related to the seismic path ICV-MOS in comparison with those related to the control path GBZ-MOS are reported in the Fig. 2. The results related to the seismic path NSY-MOS in comparison with those related to the control path NRK-MOS are reported in the Fig. 3.

From the Fig. 2, an anomaly in ICV-MSO path can be observed during 5 days before the Abruzzo earthquake and during the following aftershocks. The effect is not very evident, but it must be noted that such an anomaly is absent in the control path. Instead, a rather strong anomaly appears in the NSY signal as it is shown in the Fig. 3. An example of the

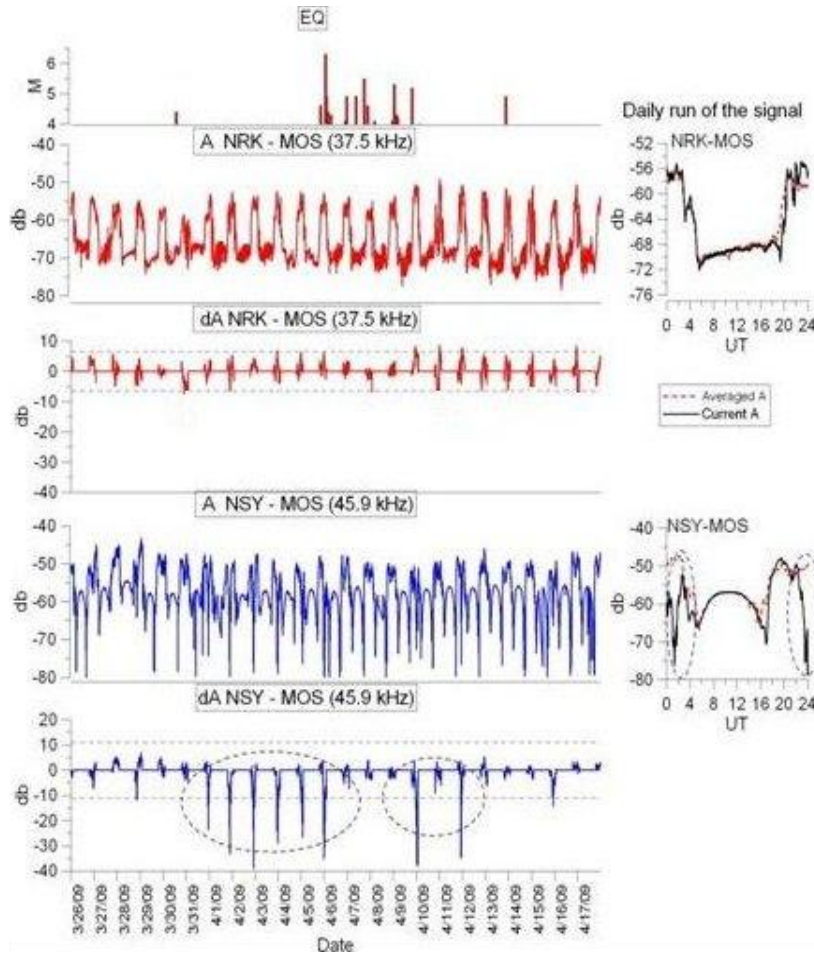

Fig. 3. Comparison of the results related to the seismic path NSYMOS and to the control path NRK-MOS. The explanation of the panels is the same as for the Fig. 2.

effect is underlined on the right bottom panel of the figure. The anomaly is observed during 6 days before the Abruzzo earthquake and as in the previous case, a similar effect is absent in the control (NRK) signal. Some difference in the amplitude of the effect, as it appears in Figs. 2 and 3, can be explained either by a frequency dependence or by the different crossing of the signal in sensitivity zones inside the perturbed area (Fig. 1). Figure 4, where the averaged data are represented, shows a summary of the previous results. From the Fig. 4, a clear depression of the signals during 56 days before the main shock only in the seismic paths stands up. Besides, it can be noted that: a) the deviation from the averaged undisturbed signal is about four times greater for the $45.9 \mathrm{kHz}$ signal than for the $20.27 \mathrm{kHz}$ signal; b) in both the cases, the depression in the signals continues during the aftershocks activity.

Then, the data collected by the Graz receiver (GRZ) were examined. Again, the signals from the Italian NSY and ICV transmitters were selected for the analysis of seismic paths. In this case, the distances $\mathrm{D}$ are shorter $(D \sim 1000 \mathrm{~km})$ than previously. The control paths were selected those from the GBZ $(D \sim 4000 \mathrm{~km})$ and from the DHO $(f=23.4 \mathrm{kHz}$, Germany, $D \sim 1000 \mathrm{~km})$ transmitters. The location of the receiver and the transmitters is shown in the Fig. 5, where as in Fig. 1, also the zone interested by the precursory activity is indicated. In this case, both the procedures of analysis mentioned in the Sect. 1 were used. 


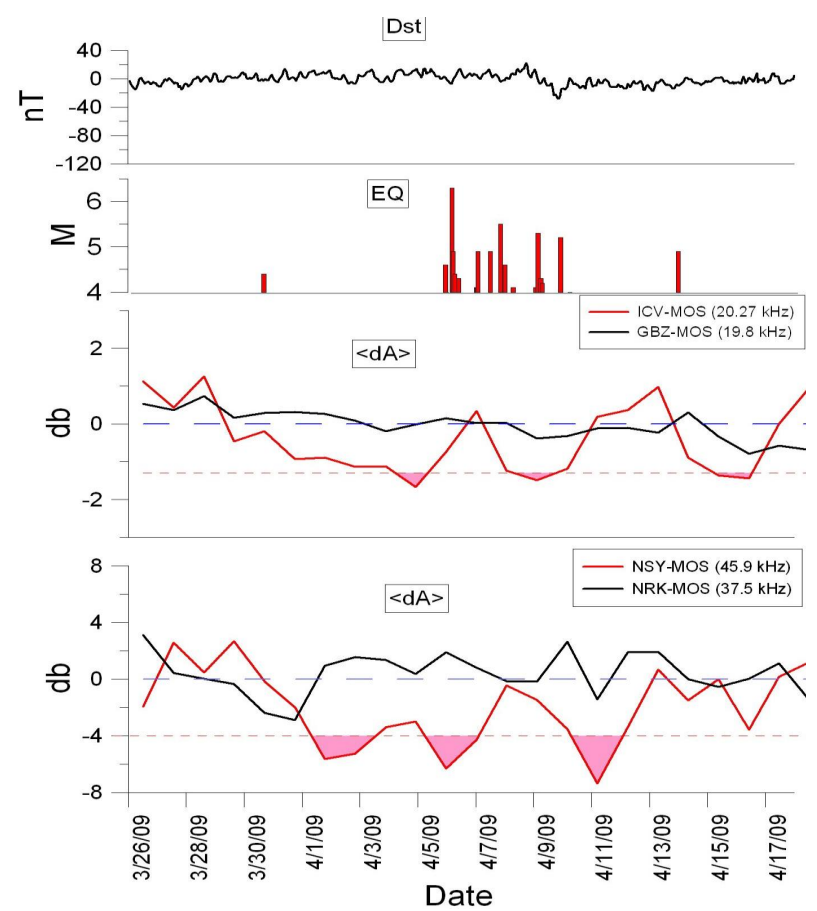

Fig. 4. In the top panels, the Dst geomagnetic index (http:// swdcwww.kugi.kyoto-u.ac.jp/dstdir/index.html) and the magnitude of the main Abruzzo earthquakes (Table 1) from 26 March to 17 April 2009 is indicated. In the next panels, the averaged nighttime residual amplitude $(<\mathrm{dA}>)$ of the signal for the seismic paths ICV-MOS and NSY-MOS (red lines) and the control paths GBZMOS and NRK-MOS (black lines) are reported. The color filled zones indicate values exceeding the $2 \sigma$ ( $\sigma$ is the standard deviation) level, indicated by horizontal dotted lines.

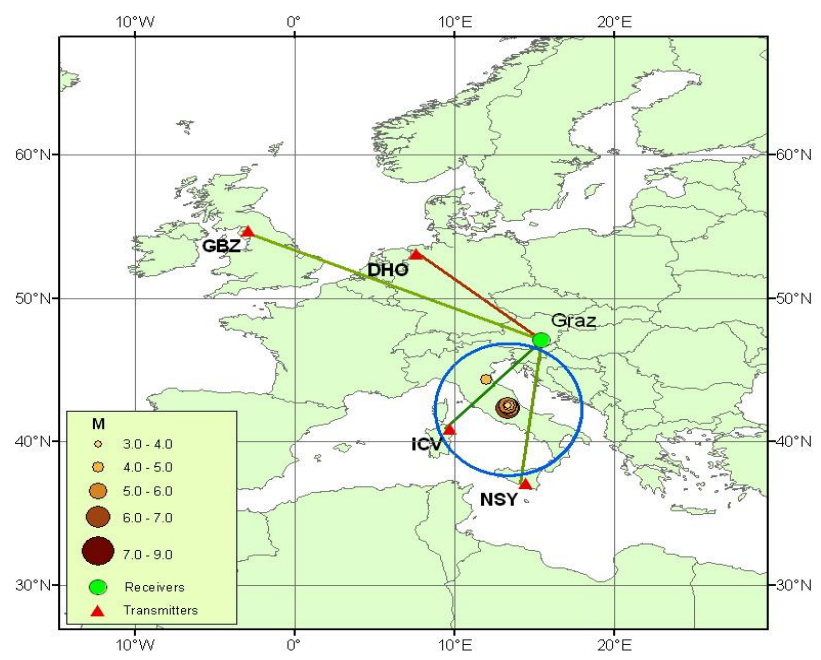

Fig. 5. Map showing the epicenters of the earthquakes occurred in the Abruzzo area in the period 1-9 April 2009. The blue circle represents the projection on the ground surface of the perturbed zone in the atmosphere-ionosphere boundary that approximately coincides with a zone of precursory activity. The seismic paths are related to the ICV (Sardinia, Italy) and NSY (Sicily, Italy) transmitters; the control paths are related to the GBZ (Great Britain) and DHO (Germany) transmitters. The receiver in Graz is indicated, too.

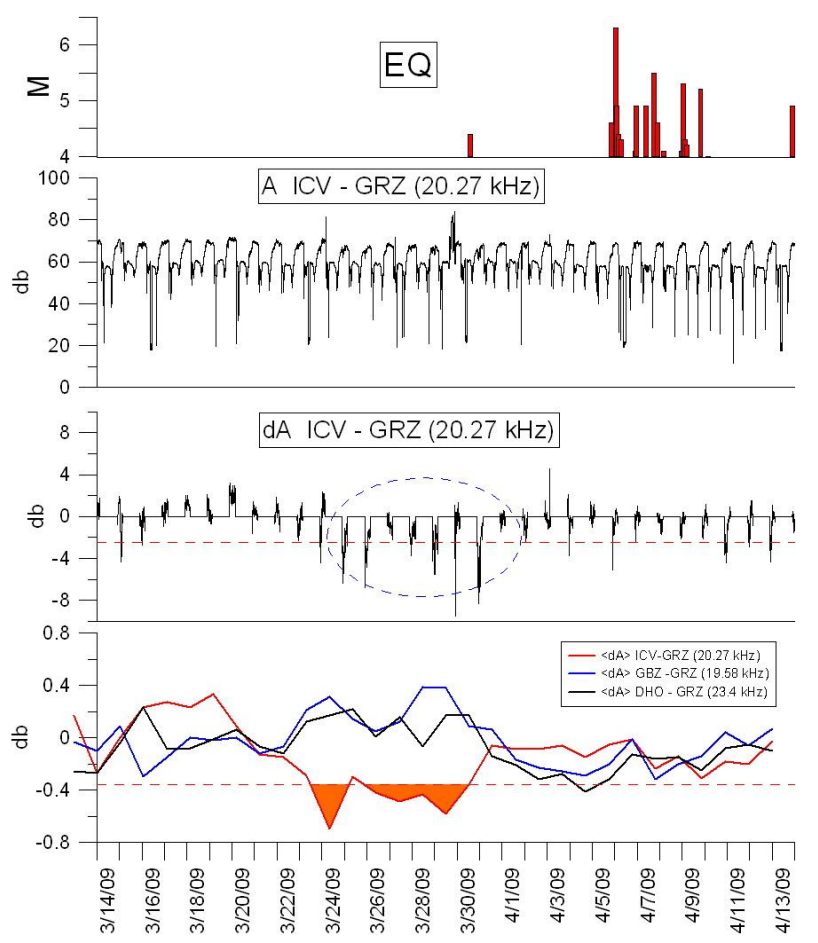

Fig. 6. In the two panels at the top, the nighttime amplitude of the ICV (Sardinia, Italy) signal and its residual amplitude is shown. In the bottom panel the averaged residual amplitude of the DHO (Germany, black line), GBZ (Great Britain, blue line) and ICV (Sardinia-Italy, red line) transmitters are reported. In last two panels, the dashed ellipse and the color filled zones indicate values exceeding the $2 \sigma$ level, that are represented by horizontal dotted lines.

The results obtained with the first analysis are presented in the Fig. 6. From the inspection of this figure, a depression in ICV signal appears from about one week before the Abruzzo earthquake, while such an effect is lacking on the two control signals.

The results obtained with the second procedure of analysis are presented in the Fig. 7. Looking this figure, it is evident the deviation of the sunset terminator times from their normal values (dashed lines) during several days before the Abruzzo earthquake for the seismic paths ICV-GRZ and NSY-GRZ and the absence of the effect for the control path GBZ-GRZ. It can be noted that the TT perturbation appears since the strongest foreshock occurred in the area.

It can be noted that using the first method, none anomaly for the seismic path from NSY transmitter was revealed, unlike the observation in Moscow. This fact can be connected with the different condition of the propagation on the paths. In fact, the paths in Moscow from Italian transmitters are rather long, about $3000 \mathrm{~km}$, and one-mode propagation exists; on the contrary the paths in Graz are short, and multimode propagation must be involved. In this situation the terminator time method seems more useful as it is revealed by the Fig. 7. 


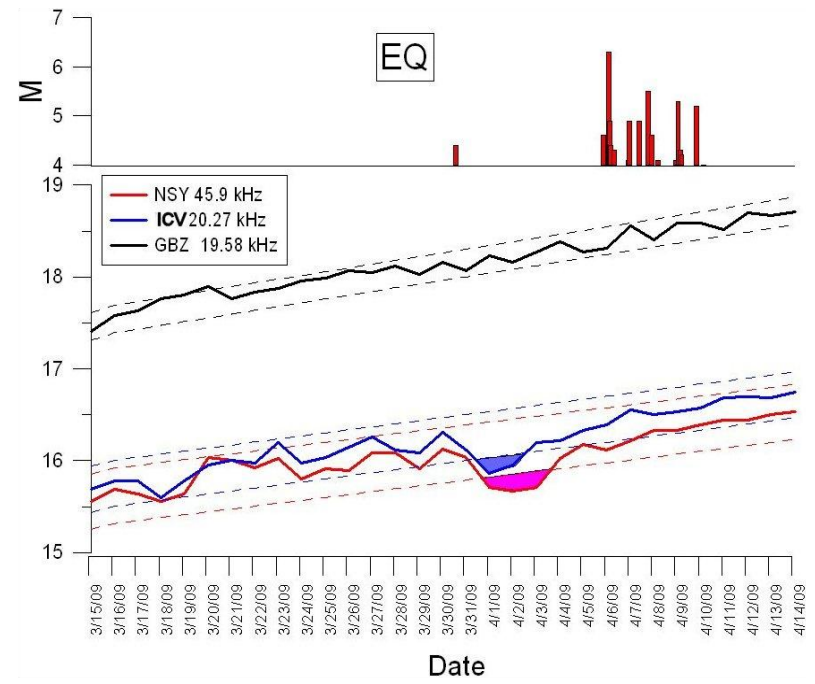

Fig. 7. Sunset terminator times for GBZ (control path, black line), IVC (seismic path, blue line) and NSY (seismic path, red line) signals, in the period 15 March-14 April. The vertical axis indicates the time in hours from the midnight. The variation ranges of the terminator times related to undisturbed situations in the three cases are indicated by dash lines. The color filled zones indicate anomalies.

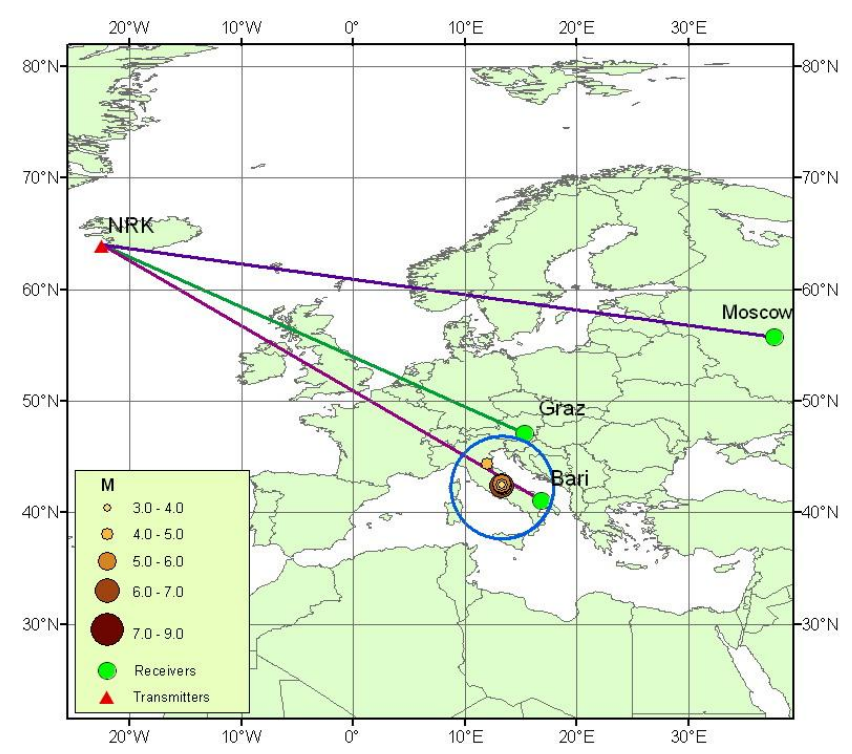

Fig. 8. Map showing the NRK transmitter and the Moscow, Graz and Bari receivers. The seismic path is for the reception in Bari, while the other ones are control paths.

Finally, the signal from the NRK transmitter recorded by the Moscow, Graz and Bari receivers was analyzed. As it is shown in the map of the Fig. 8, the NRZ-Bari path is a seismic path, while the NRZ-MOS and NRZ-GRZ ones are control paths.

The results of such an analysis are presented in Fig. 9. The effect for the Bari receiver is very strong; it appears

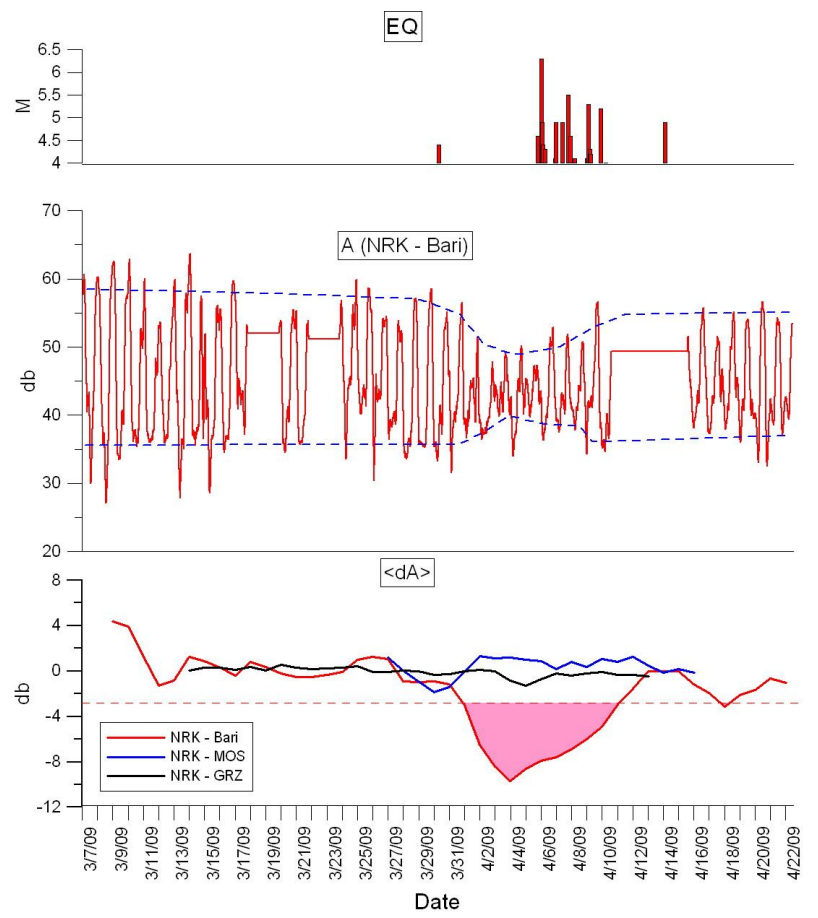

Fig. 9. In the upper panel the magnitude of the main earthquakes from 26 March to 17 April 2009 is indicated. In the next panel, the signal amplitude (A) of the NRK signal recorded in Bari in the period 7 March-22 April 2009. In the last panel the nighttime residual amplitude (dA) for the path NRK-Bari, NRK-MOS and NRKGRZ are reported. The color fill zone indicates values exceeding the $2 \sigma$ level, represented by a horizontal dotted line, for the NRK-Bari path.

about 5 days before the Abruzzo earthquake (in correspondence with the anomalies in the NSY signal in the Moscow receiver) and it continues during the aftershocks activity until 10 April. The level of the signal in nighttime decreases strongly and the day time signal grows. But, totally the daily amplitude decreases by two times with respect to the normal conditions. Such a strong effect was observed for the same path NRK-Bari only during the exceptional magnetic storm happened on October 2003 (Rozhnoi et al., 2006).

The precise mechanism able to produce the variations in the intensity of the radio signals we presented, cannot be defined. At this purpose, more data and other information must be collected. Results concerning some upward propagation from the ground and generation of turbulence in ionosphere prior the earthquakes were presented in past by different authors as Liperovski et al. (1997). So, according to our opinion, the recent model proposed by Molchanov et al. (2006) could be applied, that is the radio anomalies we presented are related to disturbances in the ionosphere turbulence produced by an upward energy flux of atmospheric gravity waves which was induced by different processes occurring during the preparation and the development of the Abruzzo sequence. 


\section{Conclusions}

Clear anomalies revealed in VLF radio signals prior the occurrence of the Abruzzo earthquake have been presented. The connection with the event appears obvious.

These results confirm that the VLF radio signal method is a reliable and an efficient tool for the revelation of precursory activity on the occasion of large earthquakes.

It must be underlined that the observations of a multistation VLF radio signals were considered. Our plan is to enlarge the network in the nearest future.

Edited by: M. E. Contadakis

Reviewed by: two anonymous referees

\section{References}

Dowden, R. L. and Adams, C. D.: Phase and amplitude perturbations on the NWC signal at Dunedin form lightning-induced electron percipitation, J. Geophys. Res., 94, 497-503, 1989.

Gokhberg, M. B., Gufeld, I. L., Rozhnoi, A. A., Marenko, V. F., Yampolshy, V. S., and Ponomarev, E. A.: Study of seismic influence on the ionosphere by super long wave probing of the Earthionosphere waveguide, Phys. Earth Planet. In., 57, 64-67, 1989.

Gufeld, I. L., Rozhnoi, A. A., Tyumensev, S. N., Sherstuk, S. V., and Yampolsky, V. S.: Radiowave disturbances in period to Rudber and Rachinsk earthquakes, Phys. Solid Earth, 28(3), 267-270, 1992.

Hayakawa, M., Molchanov, O. A., Ondoh, T., and Kawai, E.: Precursory signature of the Kobe earthquake on VLF subionospheric signal, J. Atmos. Electr., 16 (3), 247-257, 1996.

Hayakawa M., Shvets, A. V., and Maekawa, S.: Subionospheric LF monitoring of ionospheric perturbations prior to the Tokachi-oki earthquake and a possible mechanism to lithosphere-ionosphere coupling, Advances in Polar Upper Atmosphere Research, 19, 42-54, 2005.
Liperovsky, V. A., Meister, C.-V., Schlegel, K., and Haldoupis, C.: Currents and turbulence in and near mid-latitude sporadic $E$ layers caused by strong acoustic impulses, Ann. Geophys., 15, 767-773, 1997, http://www.ann-geophys.net/15/767/1997/.

Maekawa, S., Horie, T., Yamauchi, T., Sawaya, T., Ishikawa, M., Hayakawa, M., and Sasaki, H.: A statistical study on the effect of earthquakes on the ionosphere, based on the subionospheric LF propagation data in Japan, Ann. Geophys., 24, 2219-2225, 2006, http://www.ann-geophys.net/24/2219/2006/.

Molchanov, O. A. and Hayakawa, M.: Subionospheric VLF signal perturbations possibly related to earthquakes, J. Geophys. Res., 103, 17489-17504, 1998.

Molchanov, O., Rozhnoi, A., Solovieva, M., Akentieva, O., Berthelier, J. J., Parrot, M., Lefeuvre, F., Biagi, P. F., Castellana, L., and Hayakawa, M.: Global diagnostics of the ionospheric perturbations related to the seismic activity using the VLF radio signals collected on the DEMETER satellite, Nat. Hazards Earth Syst. Sci., 6, 745-753, 2006, http://www.nat-hazards-earth-syst-sci.net/6/745/2006/.

Molchanov, O. and Hayakawa, M.: Seismo-electromagnetics and related phenomena: History and latest results, TERRAPUB, Tokyo, 190 pp., 2008.

Rozhnoi, A., Solovieva, M. S., Molchanov, O. A., Hayakawa, M.: Middle latitude LF $(40 \mathrm{kHz})$ phase variations associated with earthquakes for quiet and disturbed geomagnetic conditions, Phys. Chem. Earth, 29, 589-598, 2004.

Rozhnoi, A. A., Solovieva, M. S., Molchanov, O. A., Hayakawa, M., Maekawa, S., and Biagi, P. F.: Anomalies of LF signal during seismic activity in November-December 2004, Nat. Hazards Earth Syst. Sci., 5, 657-660, 2005, http://www.nat-hazards-earth-syst-sci.net/5/657/2005/.

Rozhnoi, A.A., Solovieva, M. S., Molchanov, O. A., Hayakawa, M., Maekawa, S., and Biagi, P. F.: Sensitivity of LF signal to global ionosphere and atmosphere perturbations in the network of stations, Phys. Chem. Earth, 31, 409-415, 2006. 